\section{Editorial: Formulando hipóteses transparentemente após os resultados}

No último trabalho que me envolvi como autor, um dos revisores sugeriu que lêssemos o comentário editorial de Hollenbeck e Wright (2017), publicado no Journal of Management. A razão de tal sugestão é que um dos nossos resultados, apesar de não contradizer a hipótese original do nosso texto, apontava para efeitos não esperados. Para não haver dúvidas sobre como conduziríamos o ajuste do manuscrito, o revisor frisou que não esperava que nós reformulássemos a referida hipótese, mas que deveríamos ficar atentos a uma possivel situação de HARKing (Hypothesizing After the Results are Known), que nada mais é do que apresentar hipóteses definidas após ter os resultados em mão como se elas fossem hipóteses a priori (Kerr, 1998).

Partindo do pressuposto de que grande parte da pesquisa científica se pauta numa lógica hipotético-dedutiva, não é muito difícil de extrapolar que a prática do HARKing pode ser enquadrada como má conduta ou até como desonestidade, colocando em xeque um dos padrões mais recorrentes de se julgar proposições teóricas: a capacidade de predizer um fenômeno antes de ter acesso aos dados (Hollenbeck \& Wright, 2017). Mais ainda, como bem apontou Kerr (1998), há outros custos do HARKing, pois todo o aparato de checagem empírica dos resultados da pesquisa estaria comprometido porque não se poderia mais confiar que as hipóteses foram suficientemente pautadas em teorias desenvolvidas a priori, muito menos confiar no histórico de confrontações. O que se teria sem esse aparato seria um bom exercício criativo e de argumentação para construir hipóteses intrincadas, performáticas e dificilmente replicáveis para acomodarem os múltiplos testes realizados a posteriori.

Mas se o HARKing, sob uma lógica hipotético-dedutiva ou até falsificacionista da ciência, é algo custoso e inaceitável, por que ele persiste? Mais ainda, em algumas circunstâncias, ele seria justificável? Tentando responder à primeira pergunta, além da facilidade em se fazer hipóteses ad hoc com os resultados em mão, é inegável que a pressão por inovações no contexto acadêmico pressiona pesquisadores em buscar construir hipóteses cada vez mais sensuais, cujo uso de mediações, moderações, análises condicionais entre outros artifícios analíticos são cada vez mais frequentes. E como o uso de combinações entre variáveis permite um número relativamente grande de extrapolações com o mesmo conjunto de dados, não é muito difícil de criar hipóteses retrospectivamente.

Outro comportamento eticamente questionável cai como uma luva como mecanismo de manutenção do HARKing, que é a prática de p-hacking, em que pesquisadores tendem a mostrar (ou manipular) resultados até eles serem significativos $(p<0,05)$, ignorando aqueles que não são significativos (Head, Holman, Lanfear, Kahn, \& Jennions, 2015). Ao se reportar de forma seletiva somente aquilo que é significativo, ou pior, ao buscar a combinação de novos resultados na intenção de que algum deles seja significativo, é obvio que a história contada na seção de teoria e hipóteses precisaria ser
Luciano Rossoni (iD,

Editor da RECADM

Universidade Federal de Uberlândia, Brasil

Irossoni@gmail.com 
recontada. Por essa razão, em textos empíricos, apesar de não serem a mesma prática, HARKing e p-hacking são simbióticas, dificilmente uma podendo ser reproduzida sem a outra.

Deve-se considerar também que os pesquisadores não são os únicos atores que atuam diretamente na prática do HARKing. Em vários caros, muitos periódicos, por meio dos seus editores e revisores, acabam solicitando que os autores removam as hipóteses, variáveis e testes que não são significativos, o que aumenta inclusive o viés de publicação (Head et al., 2015). Assim, somente resultados favoráveis são publicados, varrendo para debaixo do tapete os resultados desfavoráveis. Ocorre que hipóteses refutadas são igualmente importantes para o desenvolvimento da ciência, pois boa parte da avaliação da qualidade das teorias se dá pela capacidade que essas têm de explicar a realidade. Logo, se os periódicos contarem somente a história das hipóteses vencedoras, nunca saberíamos os limites empíricos de explicação de uma determinada teoria.

Ademais, o engajamento dos revisores no processo de avaliação pode reforçar o HARKing porque ele vai muito além de sugestões e criticismo. Tanto que Strang e Siler (2015), ao investigarem o processo de revisão de artigos publicados na Administrative Science Quarterly durante o período em que o primeiro autor foi editor do periódico (2005-2009), chegaram a dizer que o processo de revisão é um reenquadramento (reframing). E estamos falando de processos de revisão no periódico seminal da área de estudos organizacionais, não de periódicos com rigor questionável. Como apontam Strang e Siler (2015), ao comparar o conteúdo dos artigos nos momentos de submissão e aprovação, o reenquadramento ocorre especialmente nas seções de articulação teórica e de discussão dos resultados, com poucas mudanças nos aspectos metodológicos e nos resultados. O reenquadramento é tão intenso que somente $40 \%$ das hipóteses foram mantidas sem reparação. Com efeito, a magnitude das alterações em tais seções e nas hipóteses leva-nos a acreditar, inevitavelmente, que nesse processo houve um forte engajamento na prática de HARKing.

Apesar das situações acima apontarem para a manutenção do HARKing e, todas elas, de alguma forma, terem o potencial de serem danosas para o desenvolvimento da ciência, o problema é ético somente quando os autores deliberadamente, e de forma secreta, alteram as hipóteses para se ajustarem aos resultados. Hollenbeck e Wright (2017) denominaram essa prática de Sharking (Secretly Hypothesizing After the Results are Known).

Obviamente, quando o revisor nos apontou para um possível HARKing, ele não estava nos induzindo a fazer um Sharking. Pelo contrário, a intenção dele de nos apresentar os textos de Kerr (1998) e de Hollenbeck e Wright (2017), além de educativa, era demonstrar que os resultados extrapolavam as hipóteses, em que parte da explicação de tais resultados não estavam contidos na argumentação teórica que apresentamos no manuscrito. O que ele aparentemente propôs é que nós apontássemos transparentemente que tais resultados não considerados a priori poderiam ter uma explicação teórica sólida, mas que, ao invés de reenquadrar a seção de teoria e hipóteses, devêssemos fazer uma discussão mais robusta. Hollenbeck e Wright (2017) 
denominaram tal prática como Tharking (Transparently HARKing in the Discussion section).

Consequentemente, a possibilidade do Tharking pode dar fundamentos para que o HARKing seja justificável, desde que não se configure como um Sharking. Tal possibilidade nos ajuda a responder a segunda pergunta, pois há sim circunstâncias que justificam o seu uso. Em primeiro lugar, deve-se considerar que, quando analisamos fenômenos organizacionais, estamos lidando com fenômenos sociais complexos. E um dos grandes problemas de se fazer pesquisa empírica acerca de tais fenômenos é que sua incerteza nos leva à impossibilidade de se criar leis universais. Tanto que Merton, um dos maiores nomes da sociologia no século XX, não devidamente ouvido devido à execração ao funcionalismo, apelava que as ciências sociais deveriam focar em desenvolver teorias de médio alcance, tratando de fenômenos sociais específicos. Com isso, não somente a amplitude, mas também a capacidade de explicação do método hipotético-dedutivo ficaria comprometida. Assim, muito dificilmente seria possível verificar fenômenos sociais que se reproduzem em contextos distintos, o que leva, necessariamente, a um maior trabalho de discussão dos resultados pelos autores. Logo, como se espera que tais discussões possam ser úteis para estudos futuros, novas hipóteses podem ser derivadas neste processo de interpretação post hoc dos resultados.

Em segundo lugar, deve-se considerar que, em ciências sociais, tudo parece óbvio, desde que se saiba a resposta (Watts, 2015). O que Watts (2015) quis dizer é que fenômenos sociais complexos podem ter diferentes níveis de explicação e, ao se confrontar com hipóteses empíricas, duas explicações antagônicas podem ser totalmente plausíveis. Como saber então quais delas efetivamente explicam determinado fenômeno? Somente depois de se ter os resultados em mão. Como bem apontaram Hollenbeck e Wright (2017), a ciência precisa ter espaço para a descoberta, logo, rejeitar o que os resultados podem nos ensinar seria como jogar boa parte do processo de evolução da ciência no lixo. Há vários exemplos de momentos eureca na ciência. Talvez o exemplo mais emblemático seja o da maçã caindo na cabeça de Newton (em um ano de pandemia devido à peste negra), despertando-o para a construção dos Principia. Então se, ao mesmo tempo, os periódicos exigem "novas descobertas", mas elas podem ocorrer pelo acaso, é evidente que os autores tendem a fazer isso por meio do Sharking (Hollenbeck \& Wright, 2017). Sendo assim, adotar uma forma de fazer isso transparentemente parece ser uma solução mais adequada.

Em terceiro lugar, deve-se considerar que efetivamente as hipóteses falham. E toda pesquisa tem um custo, muitas vezes financiada com recursos públicos. Independentemente de tais custos, ainda há uma questão de eficácia da ciência pois, se somente resultados cujas hipóteses são corroboradas são publicados, para onde vão as pesquisas cujos resultados falham? Apesar de não estarem presentes em sua maioria nos periódicos, a história da ciência é cheia de contrafactuais e de experimentos que não deram certo. E é exatamente nesse momento que muitos dos avanços mais proeminentes ocorreram, ao ponto de alguns filósofos da ciência serem 
diametricamente contra o método hipotético-dedutivo, como Feyerabend (1989), por exemplo.

Quais seriam, então, alternativas efetivas para incorporar o Tharking como processo de maturação da ciência em periódicos? Indo além, como poderíamos, ao mesmo tempo, fazer isso de forma transparente e honesta? Em primeiro lugar, nós seguimos as sugestões de Hollenbeck e Wright (2017), que apontam que o processo de hipotetizar após os resultados de forma honesta e transparente deve ser compartilhado com os revisores, pois são eles que efetivamente orientam o processo de aprimoramento dos manuscritos. Em segundo lugar, eles também sugerem que os periódicos devam incorporar, quando for o caso, uma seção na discussão dos resultados que tratem especificamente de análises post hoc. Em tal seção, não basta somente discutir os resultados. Deve haver um exercício claro de construção de teoria a posteriori para fomentar uma nova hipótese. Tal prática evitaria que o reenquadramento de hipóteses ocorresse de forma fraudulenta e secreta. Em poucas palavras, deve-se considerar seriamente um processo de finalização de artigos, tendo em mente uma lógica indutiva ou de abdução para que, de forma consistente, novos estudos sejam encorajados na intenção de avançarem em pontos cujas teorias não estão bem fundamentadas.

Em termos práticos, a partir desta edição, a RECADM adotará em seu processo editorial práticas de Tharking na intenção de desencorajar o Sharking e, ao mesmo tempo, fomentar uma discussão dos resultados mais contributiva. Inevitavelmente, em muitas situações, será necessária uma seção de análise e de discussão post hoc para demarcar tal processo. Então, com isso, esperamos ter um processo de aprimoramento dos manuscritos mais honestos e transparentes.

\section{Nesta Edição}

Esta é a primeira edição da RECADM sob a minha editoria que foi possível, deliberadamente, agrupar alguns artigos pela estreita similaridade entre os temas. Coincidentemente ou não, o tema remete à questão da sexualidade, que, infelizmente, é rechaçada em alguns periódicos da área de administração, ao ponto de muitos autores queixarem-se que tal debate não seria "possível" em alguns deles. Não é de hoje que as ditas ciências administrativas, em nome de uma questionável objetividade, tendem a normalizar os fenômenos organizacionais, ignorando, até certo ponto, de forma preconceituosa, qualquer fenômeno que transcenda essa pseudo normalidade, deixando escapar muitos dos elementos que constituem a sociedade e, mais fortemente, a experiência humana que demarca a vivência nas organizações. Se são fenômenos organizacionais, eles devem ser tratados. E quando não são tratados, é necessária alguma forma de ativismo.

Por isso, no primeiro artigo desta edição, Danuzio Weliton Gomes da Silva, Gustavo Henrique Carvalho de Castro e Marcus Vinicius Soares 
Siqueira no artigo "Ativismo LGBT organizacional: debate e agenda de pesquisa" analisam o debate sobre ativismo LGBT nas organizações, elaborando um panorama da produção científica internacional, identificando contribuições, estruturas e objetivos dos ativismos e aspectos teórico-metodológicos. A partir desse debate, os autores formularam uma agenda de pesquisa pautada nas sugestões e discussões. O levantamento bibliográfico apontou que os estudos são amparados em diferentes referenciais teóricos e mais relacionados ao paradigma interpretativista. Prevaleceu o ativismo LGBT classificado como "abordagem informal internamente responsiva", com efeitos de bem-estar psicológico e maior possibilidade de ganhos de igualdade de direitos para sexualidades dissidentes em organizações que possuem ativismo. A principal contribuição do estudo está em ser pioneiro ao tratar do ativismo LGBT, detectando linhas específicas para sua investigação em estudos organizacionais nacionais.

No segundo artigo, Camila Pinto Luna e Denise Franca Barros redigem "Uma ANTi-história sobre o processo da primeira cirurgia de redesignação sexual no Brasil: atores e suas relações sociopolíticas na ditadura civil-militar" e utilizam o arcabouço epistemo-metodológico da ANTi-History para (re)montar a rede de atores envolvida na realização da primeira cirurgia de redesignação sexual no Brasil, em plena ditadura civil-militar (1964-1985). Durante tal período ocorreram graves violações aos direitos humanos, incluindo perseguição às pessoas LGBTQ+, consideradas ameaças à segurança nacional, à família e à moral. Aproximadamente três décadas após o final desse período, foi instituída uma Comissão Nacional da Verdade, cujos relatórios foram fundamentais para desvelar os crimes e abusos cometidos. No entanto, muitas das agressões contra LGBTQ+ permaneceram turvas, sendo um exemplo o caso de uma cirurgia que passa de uma questão de saúde pública a uma questão de justiça pública. Nesta pesquisa, as autoras seguiram vestígios deixados por redes de atores associadas a diferentes instituições da administração pública e que lidam, à época, com um mesmo fenômeno de formas distintas. Assim, este trabalho contribui para estudos históricos em Administração desvelando os momentos de virada (turning points) que definem aspectos inerentes a uma rede de atores em um passado, ao identificar alguns aspectos que ainda se encontram refletidos no momento presente de instituições pertencentes à Administração Pública.

O terceiro e último artigo sobre a temática da sexualidade, intitulado "Como é ser diferente em administração? A performance de discentes gays e bissexuais em uma graduação heteronormativa", de autoria de Diego Costa Mendes e José Ricardo Costa de Mendonça, evidencia a compulsoriedade heterossexual em Administração e sua relação com a performance de discentes gays e bissexuais do curso. Os autores perceberam que a heteronormatividade evidenciada na prática social da Administração compele práticas compulsórias aos discentes, sendo regida por normas que instigam a repetição de performances legitimadas e que se amparam na compreensão linear entre corpo, sexo e desejo. Os corpos dos discentes circunscritos no curso tendem a ser regulados com base em 
imposições estabelecidas a partir da compulsoriedade heteronormativa. Para os autores, a matriz heterossexual possibilita controle social na Administração a partir de elementos legitimados que projetam performances esperadas e que buscam conformar os corpos discentes sobre identidades previamente arquitetadas.

No quarto artigo, ressalta-se a questão do gênero, no qual, com bastante propriedade, Marília Duarte de Souza, Deise Luiza da Silva Ferraz e Janaynna de Moura Ferraz redigem "As mulheres conforme a administração: uma ciência para a manutenção da opressão e da exploração?" e analisam como os estudos hodiernos no campo das ciências administrativas, os quais possuem como objeto de análise as mulheres em relações de trabalho, explicam as desigualdades existentes entre ser homem trabalhador e ser mulher trabalhadora. Para tanto, as autoras realizam uma exposição teórica acerca da cientificidade moderna, além dos principais aspectos que permeiam a questão da opressão à mulher. As autoras concluem que estudos acerca da temática são recentes e escassos, porém representam uma potencialidade para a luta das mulheres, visto que a pauta se legitima enquanto científica. Contudo, também representam limitações, pois a racionalidade científica impõe-se sobre o real e até mesmo os estudos que se propõem a serem críticos acabam, em parte, contribuindo para a naturalização da opressão.

Já no quinto artigo, "Working out loud: consegue ouvir meu trabalho?", Maruza Vieira Barboza Tavares, Vanessa Saldanha Pinheiro e Ana Augusta Ferreira de Freitas analisam a prática de Working Out Loud (WOL) na mídia social Instagram, com vistas a compreender a maneira como essa narrativa laboral é apresentada pelos indivíduos. Para tanto, foi conduzida uma coleta de dados manual, quando perfis do Instagram foram utilizados para imersão no contexto da prática do WOL. Os resultados revelam o modo como esse fenômeno abre a possibilidade para que indivíduos construam suas identidades enquanto profissionais perante o público das redes sociais, que nem sempre estão inseridos em seus ambientes de trabalho. O gerenciamento de impressões, através de legendas, tags e imagens que promovem exposições, ensinamentos e reflexões, mostra-se como elemento constituinte desse processo.

No sexto artigo desta edição, "Intraempreendedorismo no setor público por meio de ações formativas e educativas das escolas de governo brasileiras", Alcielis de Paula Neto, Magnus Luiz Emmendoerfer e Stela Cristina Hott Corrêa buscam compreender as evidências de diretrizes educativas e formativas em prol do intraempreendedorismo no setor público por intermédio das escolas de governo. Para tanto, foi realizado um estudo de casos múltiplos com três escolas de governo brasileiras dos três níveis federativos (federal, estadual e municipal). Os resultados apontam a projeção da inovação como um pseudo-empreendedorismo e a insinuação de diretrizes para um possível processo de educação para o empreendedorismo de servidores públicos, que os tornaria potenciais intraempreendedores. Dentre essas diretrizes, destacam-se a análise do contexto, o perfil do aluno, os métodos de ensino e aprendizagem, aspectos jurídicos-legais, a adequação 
da infraestrutura e o papel dos facilitadores (mentores). Conclui-se que as EGs analisadas contribuem com a criação do valor público e a valorização da imagem das organizações públicas por meio da ação intraempreendedora de seus servidores.

Por fim, no sétimo e último artigo desta edição, "Os efeitos da inteligência competitiva na eficiência de vendas: a experiência do gestor e dispersão da inteligência competitiva", Ana Carolina Molina e Valter Afonso Vieira sugerem um modelo teórico no qual a experiência do gestor e a dispersão da inteligência competitiva possuem efeitos moderadores na inteligência competitiva, alterando a eficiência em vendas. A dispersão da inteligência competitiva consiste em variações e distorções do conhecimento e a experiência do gestor compreende o tempo de empresa que o supervisor está na organização. O trabalho traz as seguintes contribuições: primeiro, quanto mais dispersa é a inteligência competitiva, pior é a eficiência de vendas no nível individual. Segundo, quanto maior é a experiência do gestor, melhor é a relação entre Inteligência Competitiva e eficiência. No mais, sugerem-se oportunidades de futuras pesquisas.

Diferentemente dos anos anteriores, esta terceira edição da RECADM não será a última do ano. Teremos o imenso prazer em encerrar o ano com a nossa primeira edição especial "Verso, Prosa, Drama e Ficção: Literatura e Organizações". Porém, como a abertura da edição ficará a cargo dos editores convidados, não haverá editorial. Então as palavras finais para o ano de 2021 ficarão nesta edição. Infelizmente, este ano foi extremamente difícil, com a perda de muitos amigos pesquisadores, alguns dele autores, revisores e colaboradores da RECADM, o que nos entristeceu muito. Foi um ano de luta, de indignação, de superação, mas também de vitórias, apesar das incertezas nos contextos social, político e acadêmico. Tais vitórias foram possíveis porque há pessoas muito dedicadas. Então, como sempre, vai o agradecimento à equipe de suporte da RECADM, especialmente para a Aline Uchida e a Flávia Vianna, que fazem, respectivamente, a revisão e a editoração da revista, auxiliando-me nesse trabalho cuidadoso de tornar os textos públicos. Devo agradecer aos revisores, a razão de ser dos periódicos enquanto instituição da ciência, pois é deles o trabalho mais importante de validação do conhecimento científico. Aos autores, que enchem a comunidade de orgulho pela criatividade, profundidade e rigor dos documentos publicados. Ao IBEPES e seus membros, pelo suporte financeiro e, ao mesmo tempo, por confiar nos rumos que a equipe editorial vem dando para o periódico. Por fim, aos leitores, que brindam a RECADM com números cada vez mais expressivos na comunidade acadêmica nacional.

Tenham uma excelente leitura e que 2022 seja muito melhor,

\section{Luciano Rossoni}

Editor da RECADM 


\section{Referências}

Feyerabend, P. K. (1989). Contra o método (Vol. 3). Rio de Janeiro: Francisco Alves. Hollenbeck, J. R., \& Wright, P. M. (2017). Harking, sharking, and tharking: making the case for post hoc analysis of scientific data. Journal of Management, 43(1), 5-18. Head, M. L., Holman, L., Lanfear, R., Kahn, A. T., \& Jennions, M. D. (2015). The extent and consequences of p-hacking in science. PLoS Biology, 13(3), e1002106.

Kerr, N. L. (1998). HARKing: Hypothesizing after the results are known. Personality and Social Psychology Review, 2(3), 196-217.

Strang, D., \& Siler, K. (2015). Revising as reframing: original submissions versus published papers in Administrative Science Quarterly, 2005 to 2009. Sociological Theory, 33(1), 71-96.

Watts, D. J. (2015). Tudo é óbvio: desde que você saiba a resposta. Rio de Janeiro: Editora Paz e Terra. 